\title{
Constituency Service and Incumbency Advantage
}

\section{Citation}

King, Gary. 1991. Constituency service and incumbency advantage. British Journal of Political Science 21(1): 119-128.

\section{Published Version}

doi:10.1017/S0007123400006062

\section{Permanent link}

http://nrs.harvard.edu/urn-3:HUL.InstRepos:4319988

\section{Terms of Use}

This article was downloaded from Harvard University's DASH repository, and is made available under the terms and conditions applicable to Other Posted Material, as set forth at http:// nrs.harvard.edu/urn-3:HUL.InstRepos:dash.current.terms-of-use\#LAA

\section{Share Your Story}

The Harvard community has made this article openly available.

Please share how this access benefits you. Submit a story.

\section{Accessibility}


This Note has shown that when a by-election produces a result that is out of line with the current national trend, then this deviation is reflected in the result at the following general election. I am grateful to a referee for the observation that similarly enduring effects may arise from atypical local or Euro-elections.

\section{Constituency Service and Incumbency Advantage}

\section{GARY KING*}

\section{INTRODUCTION}

Numerous scholars have documented a dramatic increase in incumbency advantage in US congressional elections and also state legislative elections over the past four decades.' For example, Gelman and King show that incumbents in the House of Representatives now receive about twelve extra percentage points solely as a result of holding congressional office during the campaign;' the comparable figure for most of the first half of this century was only 2 per cent. This advantage of incumbency has made members of the US House and many state legislators nearly invulnerable to electoral defeat.

Many agree that incumbents' use of constituency service explains their widening lead over challengers. The perquisites of legislative office include the franking privilege, money for travel to the constituency, staff support and other benefits that enable members of congress to provide many services to. and answer many specific requests of,

* Department of Government, Harvard University. Thanks to Mo Fiorina for helpful comments, Paul Brace for his data and the National Science Foundation for grant SES-89-09201.

'Robert S. Erikson. 'The Advantage of Incumbency in Congressional Elections', Politv', 3(1971). 395-405: Robert S. Erikson. Malapportionment. Gerrymandering. and Party Fortunes in Congressional Elections', American Political Science Review, 66 (1972), 1234-55; Albert D. Cover and David R. Mayhew, 'Congressional Dynamics and the Decline of Competitive Congressional Elections", in Lawrence C. Dodd and Bruce I. Oppenheimer, eds, Congress Reconsidered (New York: Praeger, 1977), pp. 54-72; Richard Born. 'Generational Replacement and the Growth of Incumbent Reelection in the US House'. American Political Science Review, 73 (1979), 811-17; James L. Payne. 'The Personal Electoral Advantage of House Incumbents', Americun Politics Quarterly, 8 (1980), 375-98: John R. Alford and David W. Brady, 'Partisan and Incumbent Advantage in US House Elections 1846-1986'. (Houston. Tex.: Center for the Study of Institution and Values. Rice University, 1988); John R. Alford and John R. Hibbing. 'Increased Incumbency Advantage in the House', Journal of Politics, 43 (1981), 1042-61; James C. Garand and Donald A. Gross, 'Change in the Vote Margins for Congressional Candidates: A Specification of the Historical Trends', American Political Science Revieni; 78 (1984), 17-30; John A. Ferejohn, 'On the Decline of Competition in Congressional Elections'. American Political Science Review, 28 (1977), 127-46: Candice Nelson, 'The Effects of Incumbency on Voting in Congressional Elections', Political Science Quarterly, 93 (1978-79), 665-78: Thomas E. Mann and Raymond E. Wolfinger, 'Candidates and Parties in Congressional Elections', American Political Science Review, 74 (1980), 617-32: Keith Krehbiel and John R. Wright, 'The Incumbency Effect in Congressional Elections: A Test of Two Explanations.. American Journal of Political Science. 27 (1983). 140-57: Bruce Cain. John Ferejohn and Morris Fiorina. The Personal Vote: Constituency Service and Electoral Independence (Cambridge, Mass.: Harvard University Press, 1987).

"Andrew Gelman and Gary King. "Estimating Incumbency Advantage Without Bias". American Journal of Political Science, in press. 
individual constituents. The operating budget each legislator has at his or her disposal is a reasonable aggregate measure of the amount of this constituency service, and this figure has nearly doubled in the US House in only the last ten years."

Thus, most scholars believe that increasing levels of constituency service have given incumbents their dramatic electoral advantage over the last several decades. However, as plausible as this theory is, only scattered empirical evidence directly supports this relationship. In fact, some empirical research indicates that increases in constituency service actually reduce an incumbent's inherent advantage, a wholly implausible finding which no one really believes. Indeed, Cain. Ferejohn and Fiorina review the literature seeking to explain the rise in incumbency advantage. They explain that existing empirical evidence could lead one to

the remarkable conclusion that House incumbents can close their district offices, fire their staffs, stop doing casework, abandon their quest for federal money, give up their district residences, choose committees purely on the basis of personal interest. tell the political action committees where to put their money, and still get as many votes - perhaps more - than if they continued to behave as incumbents presently do. ${ }^{+}$

Although confronted with this large body of contradictory empirical evidence, Cain, Ferejohn and Fiorina, ${ }^{5}$ and the authors of most studies they review, persist in believing that increases in constituency service partly explain the increase in incumbency advantage. ${ }^{6}$

Thus, either this relatively strong scholarly consensus is wrong, or the methodology of existing studies is lacking. As one might expect, Cain, Ferejohn and Fiorina ${ }^{8}$ and most others, favour the latter option. They suggest three methodological problems that may have accounted for these counter-intuitive findings: level of analysis problems (using survey data even though most measures of constituency service are constant within districts), measurement error and simultaneous causation. In Section II, I show that most of the methodological problems in previous studies reduce to a single problem, and in Section III I provide one way to solve this problem.

Empirical results appear in Section Iv, and Section v concludes. These sections demonstrate that, for state legislative elections, the long-hypothesized but elusive relationship between constituency service and incumbency advantage actually exists. Jewell

\footnotetext{
Norman J. Ornstein. Thomas E. Mann and Michael J. Malbin. Vital Statistics on Congress, 1989-1990 (Washington. DC: American Enterprise 1nstitute. 1990), p. 144.

${ }^{+}$Cain. Ferejohn and Fiorina. The Personal Vote. p. 123.

Cain. Ferejohn and Fiorina, The Personal Vote.

See John Blydenburgh. 'A Controlled Experiment to Measure the Effects of Personal Contact Campaigning, Midrest Journal of Political Science. 15 (1971). 365-81; Richard F. Fenno, Home Style: House Members und Their Districts (Boston. Mass.: Little, Brown, 1978): Albert D. Cover and Bruce S. Blumberg. 'Baby Books and Ballots: The Impact of Congressional Mail on Constituent Opinion'. Americun Political Science Review, 76 (1982), 347-59: Timothy E. Cook, 'Review Essay', American Political Science Revien', 77 (1983), 1017-18; Lyn Ragsdale and Timothy Cook, 'Representatives' Actions and Challengers' Reactions: Limits to Candidate Connections in the House' (paper delivered at the annual meeting of the Midwest Political Science Association. Chicago, 1984): Paul Feldman and James Jondrow, 'Congressional Elections and Local Federal Spending', American Journal of Political Science, 28 (1984). 147-64.

The strongest opponents of this near consensus are John R. Johannes and John C. McAdams, 'The Congressional Incumbency Effect: Is It Casework. Policy Compatibility, or Something Else?' American Journal of Political Science. 25 (1981), 543-67.

" Cain, Ferejohn and Fiorina, The Personal Vote.
} 
and Breaux provide an excellent overview of incumbency effects in the state legislative election data used here."

\section{I PROBLEMS}

In this section, I demonstrate how methodological problems in this literature have led to such counter-intuitive findings. It turns out that most of the methodological problems in the literature reduce to a single one: the dependent variable used in most studies is incumbent votes instead of incumbency advantage.

I formalize this problem by using Alford and Brady's distinction between (but not their measures of the incumbent's personal electoral advantage $(I)$ and the predispositions of voters to favour the incumbent's political party $(P) .{ }^{11}$ I write the expected proportion voting for the incumbent $(V$ ) as the sum of expected incumbency advantage and expected partisan predispositions:

$$
E(\boldsymbol{V})=E(I)+E(P)
$$

Denote a vector of explanatory variables that includes in the first column some measure of constituency service as $X$. The implicit model in much of the literature can be written as follows:

$$
E(I)=X \beta
$$

where $\beta$ is a vector of effect parameters, the first element of which, $\beta_{1}$, is the effect of constituency service on incumbency advantage.

The typical approach used in the literature to estimate $\beta$ is to regress the vote for the incumbent $V$ on the explanatory variables $X$. Let the first element of the least squares estimator $b, b_{1}$, refer to the estimated effect of constituency service on incumbency advantage from this regression.

To see the relationship between the estimator $b$ and the parameter $\beta$, we take the expected value of $b$ (the average over hypothetical replications of the same elections). If the expected value of a parameter estimate equals the parameter one is trying to estimate, then the estimator is said to be 'unbiased. The expected value of $b$ (which we would like to be $\beta$ ) is calculated as follows:

$$
\begin{aligned}
E(b) & =E\left[\left(X^{\prime} X\right)^{-1} X^{\prime} V\right] \\
& =\left(X^{\prime} X\right)^{-1} X^{\prime} E(V) \\
& =\left(X^{\prime} X\right)^{-1} X^{\prime} E(I+P) \\
& =\left(X^{\prime} X\right)^{-1} X^{\prime} E(I)+\left(X^{\prime} X\right)^{-1} X^{\prime} E(P) \\
& =\left(X^{\prime} X\right)^{-1} X^{\prime} X \beta+\left(X^{\prime} X\right)^{-1} X^{\prime} E(P) \\
& =\beta+\left(X^{\prime} X\right)^{-1} X^{\prime} E(P) \\
& =\beta+\gamma
\end{aligned}
$$

where $\gamma$ is a vector of coefficients from a theoretical regression of voters " partisan predispositions to vote for the incumbent candidate on the explanatory variables, $X$ $\left[\gamma=\left(X^{\prime} X\right)^{-1} X^{\prime} E(P)\right]$. The first element of $\gamma, \gamma_{1}$, is the regression of partisan predispositions on constituency service, controlling for the other explanatory variables.

If $\gamma_{1}$ is nonzero, then the estimated effect of constituency service on incumbency

"Malcolm E. Jewell and David Breaux. "The Effect of Incumbency on State Legislative Elections", Legislative Studies Quarterly 13 (1989), 495-514.

10" Alford and Brady, Partisan and Incumbent Advantage. 
advantage, $b_{1}$, is biased. By definition, in the short term, constituency service can have no direct effect on partisan predispositions. However, when partisan predispositions drop enough to put an incumbent in danger of losing the next election, he or she will likely step up service to their district so that the incumbency effect $(I)$ might compensate. Because of this simultaneity effect, $\gamma_{1}$ is probably negative.

For example, consider two newly elected representatives, one elected with 51 per cent of the vote and the other with 65 per cent. Since these candidates were not incumbents during this election, these figures are reasonable estimates of partisan predispositions, $P$, in their districts. Certainly the candidate with 51 per cent is likely to feel more vulnerable and may therefore do more constituency service, other things being equal. More generally, when partisan predispositions decrease, constituency service is likely to increase (i.e., $\gamma<0$ ). (In this example, incumbency advantage, which cannot occur until the second election, can have no effect on the level of constituency service.)

For specific representatives who have been elected several times, distinguishing which part of their observed vote, $V$, is partisan predispositions, $P$, and which is incumbency advantage, $I$, is difficult or impossible. Indeed, no measures have ever been proposed. However, we should be fairly certain that $P>I$, since no one has even claimed that incumbency advantage is as high as 15 per cent, ${ }^{11}$ whereas $V-I=P$ must be at least three times as large for incumbents (since incumbents are all winners and thus $V>0.5$ ). Thus, the most significant part of $V$ is still $P$, and the directions of causality are probably as follows: when partisan predispositions drop, the level of constituency service increases to compensate, which, in turn, increases the incumbency advantage. Thus, $\beta_{1}>0$ and $\gamma_{1}<0$.

The methodological problem is that $b_{1}$ is an unbiased estimate of $\beta_{1}+\gamma_{1}$ instead of $\beta_{1}$. Furthermore, since $\gamma_{1}$ is probably negative, computing $b_{1}$ gives an answer that is too small and possibly negative. This is the primary reason previous scholars have found the effect of constituency service on incumbency advantage to be near zero or negative. Rivers and Fiorina derive a similar result from a formal model of a typical legislator's incentives. ${ }^{12}$

Because the amount of constituency service that members of a legislature perform depends in part on the partisan predispositions of voters in their districts, $P$, a crosssectional analysis of all the districts within a year is unlikely to reveal the desired evidence. Take, for example, a simple model where all members gather and spend resources to maximize their chances of re-election. The average level of constituency service in the House probably depends on the availability of the resources that members will seek out (such as the franking privilege, funds to hire staff, etc.). However, variation in constituency service across members within any one congress would depend more on differences in partisan predispositions (as a measure of expected vote) than anything else. To use constituency service for a particular member of the House as an explanatory variable entails the assumption that constituency service is not determined by the partisan predisposition of that district, which is equivalent to assuming that members do not use the means at their disposal to improve re-election prospects. Although one might reasonably argue that a member has goals in addition to re-election, it would be folly

"See Gelman and King, 'Estimating Incumbency Advantage without Bias'.

12 Douglas Rivers and Morris P. Fiorina. 'Constituency Service. Reputation, and the Incumbency Advantage', in Morris P. Fiorina and David Rohde, eds, Home Style and Washington Work (Ann Arbor: University of Michigan Press, 1989). 
to think that the vast majority of members have no interest in the next election. ${ }^{13}$ Unfortunately, most previous researchers make precisely this mistake.

\section{SOLUTIONS}

The solution to the methodological problems described in the previous section requires two components: first, we need a measure of the incumbency advantage, $I$, and use it, instead of votes, $V$, in the constituency service regression. Secondly, we should not use actual constituency service for individual members as a measure (since it is endogenous). Instead, we use the average level of resources that members could use for constituency service - the legislative operating budget. Included in a member's legislative operating budget is money for mailings, travel back to the district, phone calls, newsletters and staff; these and other items are primarily used to provide services to the member's constituents. Because this measure is the same for each legislator in a state for each year, it is exogenous to individual members' resource-seeking and constituency service activities in the short term. ${ }^{14}$ Although members' legislative operating budgets may be endogenous in the long run, they are unlikely to be a function of $P$ for a single legislative term.

We therefore require a measure of incumbency advantage averaged over districts for a single year for each legislature. ${ }^{15}$ Since incumbency advantage and constituency service are much more variable within and across state legislatures than within the US House, state legislatures are a particularly convenient place to test this hypothesis. The primary difference between state legislatures and the US congress relevant to this analysis is that both incumbency advantage and each legislator's operating budget are larger in the US congress. No evidence or theory exists to indicate that the relationship between the two differs at all in these legislative bodies. On the other hand, the larger variation in operating budgets (and thus constituency service) across states and years than across years in congress makes state legislative elections a particularly appropriate place to test this hypothesis.

To estimate the incumbency advantage, $I$, for a particular state legislature and election year, I use Gelman and King's unbiased estimator based on a regression of a pair of election years. ${ }^{16}$ To estimate this quantity, denote $v_{1 i}$ and $v_{2 i}$ as the Democratic proportions of the two-party vote in district $i$ in a state in elections 1 and 2, respectively.

${ }_{13}$ Note that using a lagged value of $P$ as a control, as some scholars have done, is not a solution to this endogeneity problem. Indeed, in some cases, introducing an additional control variable can actually cause more bias and inefficiency than less, especially when testing causal hypotheses.

${ }_{14}$ This measure was studied in the US Congress by Nelson W. Polsby, 'The Institutionalization of the House of Representatives', American Political Science Review, 62 (1968), 144-68. Table 6.

13 In addition to the endogeneity problems caused by using constituency service at the district level, no measure of district-level incumbency advantage has ever been proposed. I therefore move to the legislature as the level of analysis. Because this produces only a single number for each election year. we would need a very long time-series of congressional election years to study the effect of constituency service. I therefore move to state legislative data.

it Gelman and King. 'Estimating Incumbency Advantage', also show that every other measure of incumbency advantage proposed in the literature is biased or inconsistent. 
Let $R_{i}$ equal 1 if a Democratic incumbent runs for re-election, 0 if no incumbent runs, and -1 if a Republican incumbent is seeking re-election, in election 2. In addition, $P_{i}$ is 1 if the Democrat wins election 1 and -1 if the Republican wins. For a pair of election years, the estimate of the incumbency advantage $I$ on a linear regression of votes on incumbency status, controlling for previous votes and partisan swing:

$$
E\left(v_{2 i}\right)=\beta_{0}+\beta_{2} P_{i}+\beta_{1} v_{1 i}+I R_{i}
$$

where the least squares estimate of $I$ is the estimate of incumbency advantage.

An important topic for future research is working out how to measure incumbency advantage in states with multi-member districts. Since this problem has not yet been solved (or even analysed in detail), I restrict the present analysis to the lower house of state legislatures which use only single member districting systems. I use all elections for which data exist, that is even numbered years from 1968 to 1986 in thirteen states. ${ }^{17}$

I estimate $I$ for every adjacent pair of years in each of these states in which district lines do not change. The results (and the list of states) appear with their standard errors in Table 1.

A convenient summary of the information in Table 1 appears in Figure 1. The curve in Figure 1 is a smooth version of a histogram called a "kernel density estimate.." In addition, I represent each measure of incumbency advantage (for one state and year) with a short vertical line at the bottom of the graph; in this way, Figure 1 helps to illuminate patterns in the data without losing much information from Table 1. In most of the elections, incumbents receive just under five extra percentage points, solely because they were previously elected. Another large group of states have incumbency advantages of about seven to twelve percentage points. Eight of the estimates are negative, but these generally have larger standard errors; none is significantly negative. The variability across states and over time is also considerable.

\section{EMPIRICAL RESULTS}

The measures of incumbency advantage reported in Table 1 serve as the dependent variable. I use the legislative operating budget as a measure of the available resources that could be used for constituency service. The measure is in units of ten thousand 1986 inflation-adjusted dollars. This variable is not perfect since these funds can be and are used by legislators for items other than constituency service. However, because these budget figures are measured at the level of the legislature, considerable portions of this measurement error will cancel out in the aggregation process. In addition, a standard statistical result is that any remaining random measurement error will bias the estimate towards zero. so the true coefficient will be larger than the one I estimate below. Since this stacks the methodological deck against finding the expected effect, future research should develop better time-series-cross-sectional measures. Nevertheless, any effect found below is even stronger support for this procedure and the constituency

\footnotetext{
These data are available from the ICPSR and were originally collected under the direction of Professor Malcolm Jewell.

${ }^{1 *}$ See B. W. Silverman. Density Estimation for Statistics and Data Analysis (London: Chapman and Hall, 1986). When one draws a histogram, a choice must be made as to the size and number of bars. which effectively provides a compromise between averaging to find patterns (few bars) and accurately representing the original data (many bars). For kernel density estimates, this same compromise is made by the value of the 'smoothing parameter'. For the example in the text, I use half the value of the standard error for each observation as its smoothing parameter.
} 


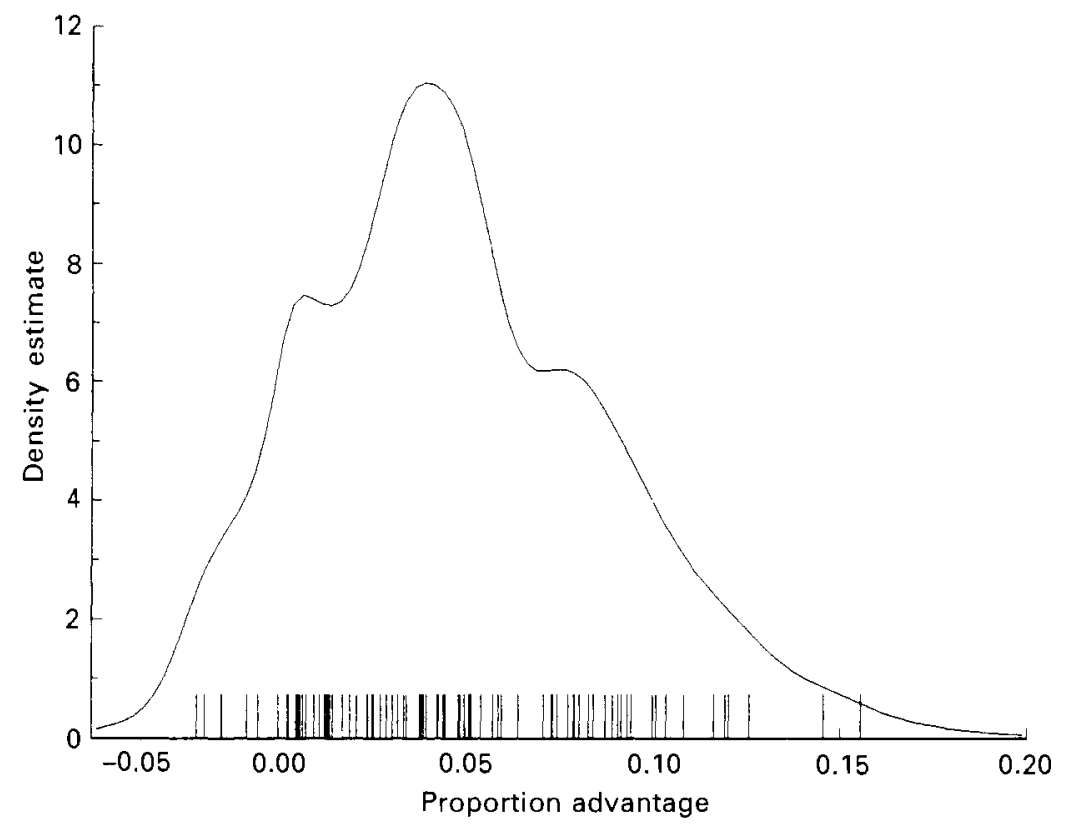

Fig. 1. Incumbency advantage, thirteen states, 1968-86

Note: The curve in this figure is a smooth version of a histogram called a 'Density Estimate'. and can be interpreted as a histogram: the area under the curve between two values of incumbency advantage (on the horizontal axis) gives the approximate proportion of observations falling in that range. The total area under the curve is equal to 1.0. Each datum is also represented in the figure with a small vertical line at the bottom of the graph, hence preserving as much information as possible.

Source: Table 1.

service hypothesis. I also include the legislator"s salary and twelve $0 / 1$ indicator variables to represent the thirteen states, as controls. These indicator variables guard against the possibility that the proportion of the legislative operating budgets that could be used for constituency service varies across states. In other words, including the state indicator variables equalizes what are at first very different state political systems and enables one to test for the effect of constituency service within each state. Including salary as a control ensures that the coefficient for operating budget reflects constituency service and not the attraction that incumbents might have for the job because of its financial compensation. ${ }^{14}$

Finally, instead of a least squares regression, I use the standard errors in Table 1

${ }^{14}$ The budget and salary data are taken from Paul Brace, "The American Statehouse Transformed: Longitudinal and Cross-Sectional Analysis of Changing Legislative Resources' (New York: New York University, mimeo, 1987). 


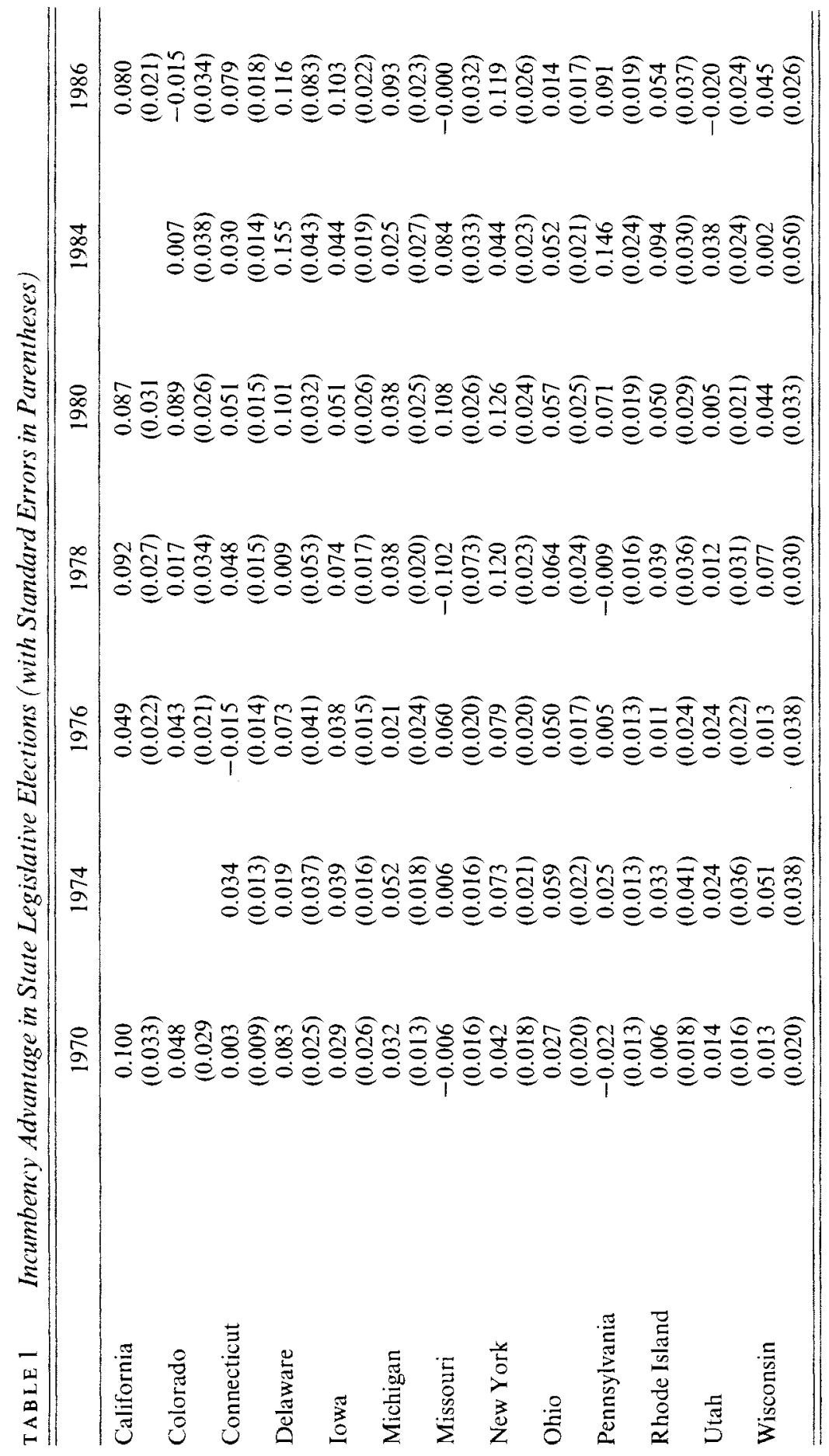


as weights in a weighted least squares regression analysis. This procedure weights those observations about which we have most information the heaviest. ${ }^{20}$

T A B LE 2 Weighted Least Squares Regressions of Incumbency Advantage

\begin{tabular}{|c|c|c|c|c|}
\hline Variables & $b$ & s.e. & $b$ & s.e. \\
\hline Constant & -0.1157 & 0.0508 & -0.2513 & 0.0989 \\
\hline Budget & 0.0154 & 0.0040 & 0.0230 & 0.0068 \\
\hline Salary & 0.0045 & 0.0039 & 0.0098 & 0.0067 \\
\hline Colorado & 0.1288 & 0.0464 & 0.2427 & 0.0830 \\
\hline Conecticut & 0.1217 & 0.0462 & 0.2430 & 0.0848 \\
\hline Delaware & 0.1777 & 0.0499 & 0.2962 & 0.0917 \\
\hline Iowa & 0.1427 & 0.0447 & 0.2674 & 0.0842 \\
\hline Michigan & 0.0698 & 0.0341 & 0.1281 & 0.0511 \\
\hline Missouri & 0.1099 & 0.0436 & 0.2397 & 0.0780 \\
\hline New York & 0.0381 & 0.0225 & 0.0967 & 0.0311 \\
\hline Ohio & 0.1098 & 0.0403 & 0.2032 & 0.0715 \\
\hline Pennsylvania & 0.0424 & 0.0296 & 0.0944 & 0.0452 \\
\hline Rhode Island & 0.1409 & 0.0518 & 0.2772 & 0.0998 \\
\hline Utah & 0.1232 & 0.0510 & 0.2472 & 0.0976 \\
\hline Wisconsin & 0.1012 & 0.0419 & 0.2021 & 0.0709 \\
\hline $\operatorname{Lag}(\operatorname{IncAd})$ & & & -0.0694 & 0.1389 \\
\hline$n$ & \multicolumn{2}{|c|}{88} & \multicolumn{2}{|c|}{52} \\
\hline
\end{tabular}

The first two columns of numbers in Table 2 represent the main test of the constituency service hypothesis. The second pair of columns add the lagged value of the dependent variable in the regression as an example of one of the tests I ran for autocorrelation. The coefficient on the legislative operating budget did not drop; indeed, it significantly increased. This is additional evidence of the validity of the first regression. However, since including this lagged term requires dropping one observation for each cross-section and redistricting period (reducing the sample size from 88 to 52). I focus on the first regression. ${ }^{21}$

The two numbers of primary interest in this table are the coefficient on the budget figure and its standard error, both presented in boxes. The coefficient is significant and positive, indicating that constituency service has a systematic effect on incumbency

211 Strictly speaking, the disturbance term in this model comes only from the uncertainly in estimating $I$. That is, $\hat{I}=X \beta+\epsilon$. One could add another disturbance term, allowing $I$ itself, rather than just $\hat{I}$, to be a random variable: $E(\hat{I})=I=X \beta+\epsilon$. In theory, this would produce slightly more efficient estimates (if this alternative model is true), but using the simpler model, even if this model is right, causes no statistical bias. Furthermore, a recent paper demonstrates that estimators of the two models produce virtually identical inferences in practice, both for coefficients and standard errors. See John E. Jackson, 'Estimation of Variable Coefficient Models' (paper presented at the annual meeting of the Midwest Political Science Association, Chicago, 1990).

"I I also did tests for autocorrelation and nonstationarity in incumbency advantage and in the explanatory variables. These tests included additional lag terms, linear and quadratic trend terms. using difference of incumbency advantage and other techniques. None of these materially altered my substantive conclusions. 
advantage. Specificaily, an extra $\$ 10,000$ added to the budget of the average state legislator gives this incumbent an additional 1.54 percentage point advantage in the next election. The 95 per cent confidence interval ranges from an effect of 1.14 to 1.94 percentage points, so we can be sure both that the effect is positive and that it is fairly strong. ${ }^{22}$

$\checkmark$ CONCLUSION

This Note addresses the long-standing discrepancy between scholarly support for the effect of constituency service on incumbency advantage and a large body of contradictory empirical evidence. I first show that many of the methodological problems noticed in past research reduce to a single measurement problem that is readily resolved. The core of the Note then provides among the first systematic empirical evidence for the constituency service hypothesis. Future research still needs to demonstrate this effect in data from congressional elections, a more difficult task given the more limited variation of constituency service and incumbency advantage and the small number of observations.

$\because$ The boot-strapped standard error is 0.006 , so we can have confidence that even if certain model assumptions are invalid, this coefficient is still significantly greater than zero. I also tested for a nonlinear relationship by using the log of the budget and salary figures. These nonlinear results were somewhat stronger than those presented in Table 2, indicating diminishing returns for successively larger increments in the legislative operating budget. The results in the text are the best linear approximation to this nonlinear result and also are simpler to explain and interpret. 